triggered by impulses arising spontaneously from damaged spinal cord neurons. This is in accord with a previous report of structural and functional changes in the spinal cord in the acute stage after deafferentation. ${ }^{9}$

Ramachandran and Hirstein ${ }^{10}$ reviewed the studies of the topographical reorganisation of the cerebral cortex after limb amputations and concluded that the mechanism of phantom experiences is "remapping" of specific brain areas. The present study did not consider this question. However, the diversity of the illusionary experiences of movement reported by our patient suggests a more diffuse cortical reorganisation. This is more in keeping with the neuromatrix theory, ${ }^{9}$ and the presence of "diffuse neural matrix".

The occurrence of phantom limb phenomena in patients with non-traumatic CNS lesions had also been previously described in a few patients with stroke. Halligan $e t \mathrm{al}^{11} \mathrm{car}-$ ried out a detailed study of a 65 year old man with severe left sided weakness, sensory loss, and hemianopia who, for several weeks, consistently reported a phantom (or supernumerary) third limb. Like our patient, he had good insight into his neurological deficits and his behaviour was completely rational, suggesting that the phantom experience was not a delusional belief but a direct result of organic brain damage.

A M O BAKHEIT Beauchamp Centre, Mount Gould Hospital, Plymouth Pl4 7QD, UK

1 Ribbers G, Mulder T, Rijken R. The phantom phenomenon: a critical review. International phenomenon: a critical review. International 86.

2 Jensen TA, Krebs B, Nielsen J, et al. Nonpainful phantom limb phenomena in amputees: incidence, clinical characteristics and temporal course. Acta Neurol Scand 1984 70:407-14.

3 Heusner AP. Phantom genitalia. Transactions of the American Neurological Association 1950;75 128-31.

4 Kroner K, Knudsen UB, Lundby L, et al. Longterm phantom breast syndrome after mastectomy. Clin F Pain 1992;8:346-50.

5 Burke DC, Woodward JM. Phantom movement and phantom feeling in complete paraplegic patients. Handbook of Clinical Neurology 1976; 26:489-99.

6 Sherman RA, Sherman CJ, Bruno GM. Psychological factors influencing chronic phantom logical factors influencing chronic phantom
limb pain: an analysis of the literature. Pain limb pain: an an

7 Calvin WH, Devor M, Howe J. Can neuralgias arise from minor demyelinization? spontaneous firing, mechanosensitivity and after-discharge from conducting axons. Exp Neurol 1982;75 755-63.

8 Melzack R. The gait control theory 25 years later: new perspectives on phantom limb pain. In: Bond MR, Charlton JE, Woolf CJ, et al, eds. Proceedings of the VI th World Congress on Pain. Amsterdam: Elsevier, 1991:9-21.

9 Wall PD. On the origin of pain associated with amputation. In: Siegfried J, Zimmermann M, eds. Phantom and stump pain. Berlin: Springer, 1981 .

10 Ramachandran VS, Hirstein W. The perception of phantom limbs. The DO Hebb Lecture. of phantom limbs. The

11 Halligan PW, Marshall JC, Wade DT. Three arms: a case study of supernumerary phantom limb after right hemisphere stroke. $\mathcal{F}$ Neuro Neurosurg Psychiatry 1993;55:159-66.

\section{Vestibular evoked myogenic potentials in multiple sclerosis}

Myogenic potentials generated by a click evoked vestibulospinal reflex can be easily recorded from the tonically contracting ipsilateral sternocleidomastoid muscle (SCM). These "vestibular evoked myogenic potentials" (VEMPs) are abolished by selective vestibular nerve section ${ }^{1}$ as well as by cer- tain peripheral vestibular diseases. ${ }^{2-4}$ Click sensitive primary vestibular neurons arise from the saccular macula in the guinea pig $^{5}$ and electrical stimulation of these neurons in the cat evokes inhibitary postsynaptic potentials in ipsilateral SCM motor neurons which are abolished by transection of the medial vestibulospinal tract. ${ }^{6}$ These clinical and neurophysiological data suggest that VEMPs are mediated by a pathway consisting of the saccular macula, its primary neurons, vestibulospinal neurons from the lateral vestibular nucleus, the medial vestibulospinal tract, and finally motor neurons of the ipsilateral SCM. Therefore a lesion anywhere in this pathway could result in abnormal VEMPs. We studied VEMPs in three patients with definite multiple sclerosis ${ }^{7}$ to search for lesions in the vestibulospinal pathways.

Patient 1 , a woman aged 30 , and patient 2 , a man aged 32, both showed dysarthria, cerebellar ataxia, bilateral internuclear ophthalmoplegia, and a spastic tetraparesis. Patient 3 , a woman aged 36 , showed cerebellar ataxia and a spastic tetraparesis only. Apart from VEMPs, all patients underwent auditory evoked potential (AEP) testing as well as MRI.

Our recording methods have been described previously. ${ }^{2}{ }^{3}$ Briefly, surface EMG activity was recorded in the supine patient from symmetric sites over the upper half of each SCM with a reference electrode on the
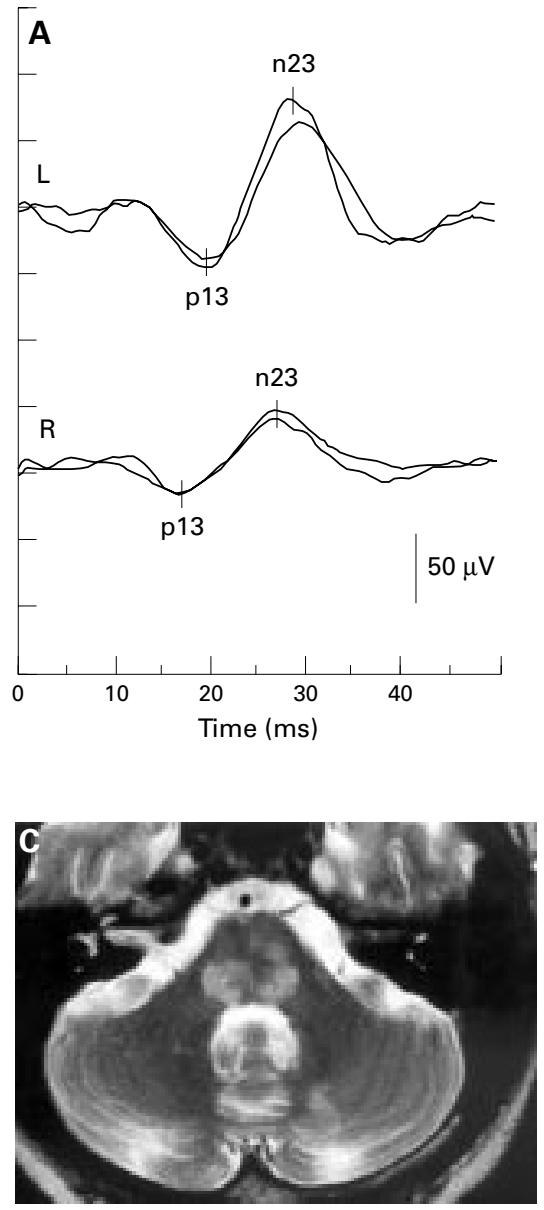

(A) VEMPs, (B) AEPs, and (C) MRI from patient 1. VEMPs are significantly bilaterally, asymmetrically prolonged on both sides. On the left: $p 13=19.8 \mathrm{~ms}, n 23=29.2 \mathrm{~ms}$; on the right: $p 13=16.7 \mathrm{~ms}, \mathrm{n} 23=26.9 \mathrm{~ms}$. $L=$ responses from the left $S C M$ to the left ear stimulation; $R=$ responses from the right SCM to the right ear stimulation. AEPs on the left were normal, while on the right wave $V$ was delayed to $6.5 \mathrm{msec}$ (normal $<5.9 \mathrm{~ms}$ ) and the $I-V$ interpeak latency was prolonged to $5.1 \mathrm{~ms}$ (normal $<4.4 \mathrm{~ms}$ ). T2 weighted MRI shows high intensity lesions in the pontine tegmentum involving the vestibular nuclei and vestibulospinal tracts bilaterally. lateral end of the upper sternum. During the recording, the patients were instructed to rotate their heads to the opposite side to the stimulated ear to activate the SCM. Rarefaction clicks $(0.1 \mathrm{~ms}, 95 \mathrm{~dB}$ normal hearing level) were presented through a headphone. The responses to 100 stimuli were averaged twice. Our normal control values have been reported previously. ${ }^{23}$ Briefly, all normal subjects show a biphasic response (p13-n23) from the ipsilateral SCM. The mean (SD) of the positive peak $(\mathrm{p} 13)=11.4(0.8) \mathrm{ms}$; the mean (SD) of the negative peak $(\mathrm{n} 23)=20.8$ (2.3) ms. We defined the mean+2 SD as the upper limit of the normal range - that is, $\mathrm{p} 13=13 \mathrm{~ms}$ and $\mathrm{n} 23=25.4 \mathrm{~ms}$

All of the six sides in three patients showed biphasic responses (p13-n23) with significantly prolonged latencies. Patient 1 showed prolonged p13 and $\mathrm{n} 23$ on both sides (right p13 $=16.7, \mathrm{n} 23=26.9 \mathrm{~ms}$; left p13=19.8, $\mathrm{n} 23=29.2 \mathrm{~ms}$, figure A). Patients 2 and 3 showed bilaterally prolonged p13 (right p13 $=15.3$, left p13=16.5 ms (patient 2), and right p13 $=15.0$, left p13 $=18.5 \mathrm{~ms}$ (patient 3 ). In patient 1 the latency of the left p13 (19.8 $\mathrm{ms}$ ) was longer than that of the right p13 $(16.7 \mathrm{~ms})$; in this patient the interpeak latency between waves I and V of the AEP was significantly prolonged only on the right (right $=5.14 \mathrm{~ms}$, left $=4.30 \mathrm{~ms}$, figure B).

T2 weighted MRI of patient 1 showed high intensity areas in the tegmentum of the pons

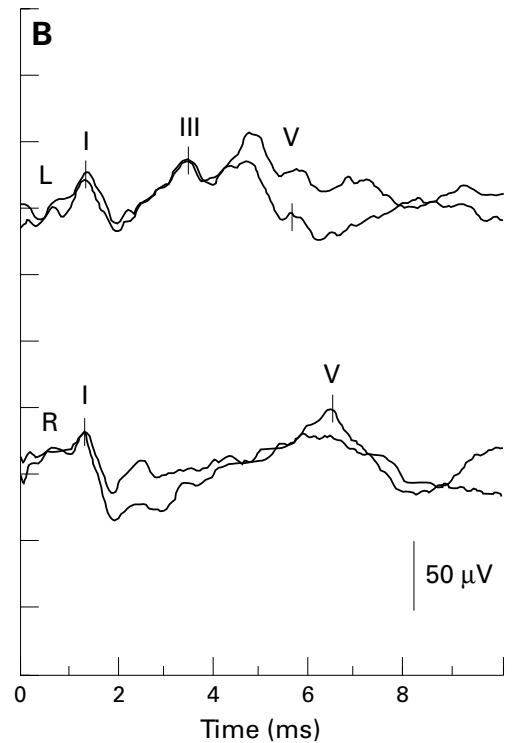


on both sides involving the vestibulospinal tracts bilaterally (figure C). Patients 2 and 3 also had high intensity areas in the same areas. Apart from lesions in this area, all showed high signal intensity areas in the cerebral white matter.

This preliminary study shows that latencies of a vestibulospinal reflex can be prolonged in multiple sclerosis. As in these three patients the VEMPs were remarkably delayed rather than simply abolished as occurs in patients with peripheral vestibular lesions, ${ }^{2-4}$ the VEMP delay could be attributed to demyelination either of primary afferent axons at the root entry zone or secondary vestibulospinal tract axons rather than to lesions involving vestibular nucleus neurons. The MRI findings in these patients were not inconsistent with this proposition. Measurement of VEMPs could be a useful clinical test to evaluate function of the vestibulospinal pathway and for detecting subclinical vestibulospinal lesions in suspected multiple sclerosis.

This study was supported by a Research Grant from the Intractable Diseases Fund (Vestibular Disorders) of the Ministry of Health and Welfare, Japan (1999).

KEN SHIMIZU TOSHIHISA MUROFUSH Neuro-otology Clinic, Department of Otolaryngology, Faculty of Medicine, University of Tokyo, 7-3-1 Hongo, Tokyo 113-8655, fapan MASAKI SAKURAI

Department of Physiology, Teikyo University School of Medicine, Tokyo, fapan

MICHAEL HALMAGYI

Neurology Department, Royal Prince Alfred Hospital, Sydney, Australia

Correspondence to: Dr Toshihisa Murofushi toshi-tky@umin.ac.jp

1 Colebatch JG, Halmagyi GM, Skuse NF. Myogenic potentials generated by a clickevoked vestibulocollic reflex. 7 Neurol Neurosur Psychiatry 1994;57:190-7.

2 Murofushi T, Matsuzaki M, Mizuno M. Vestibular evoked myogenic potentials in patients with acoustic neuromas. Arch Otolaryngol Head Neck Surg 1998;124:509-12.

3 Murofushi T, Halmagyi GM, Yavor RA, et al. Vestibular evoked myogenic potentials in vestibular neurolabyrinthitis; an indicator of inferior vestibular nerve involvement? Arch Otolaryngol Head Neck Surg 1996;122:845-8.

4 Heide G, Freitag S, Wollenberg I, et al. Click evoked myogenic potentials in the differential diagnosis of acute vertigo. 7 Neurol Neurosur Psychiatry 1999;66:787-790.

5 Murofushi T, Curthoys IS. Physiological and anatomical study of click-sensitive primary vestibular afferents in the guinea pig. Acta Otolaryngol (Stockh) 1997;117:66-72.

6 Kushiro K, Zakir M, Ogawa Y, et al. Saccular Kushiro K, Zakir M, Ogawa Y, et al. Saccular
and utricular inputs to sternocleidomastoid motoneurons of decerebrate cat. Exp Brain Res motoneurons of dece

7 Poser CM, Paty DW, Scheinberg L, et al. New diagnostic criteria for multiple sclerosis: guidelines for research protocols. Ann Neurol 1983; 13:227-31.

\section{Sensory ataxia as the initial clinical symptom in $\mathrm{X}$-linked recessive bulbospinal neuronopathy}

$\mathrm{X}$-Linked recessive bulbospinal neuronopathy (X-BSNP) has previously been described as a disease in which the first clinical symptoms which occur concern the motor system. A weakness of the shoulder and pelvic girdle muscles as well as cramps and muscle pain in the proximal limbs are normally found in the early stages. ${ }^{1-3}$ The onset of $\mathrm{X}$-BSNP generally ranges between the ages of 25 and 50 years; the disorder then shows a slow but continuous progression of symptoms. ${ }^{13}$ An involvement of facial and bulbar musculature with fasciculations and atrophy of these muscles and, therefore, often dysarthria and dysphagia, are common symptoms of an advanced stage. ${ }^{13}$ Nevertheless, life expectancy does not seem to be considerably reduced. ${ }^{1}$ Sensory impairment was reported to be minimal or non-existent. ${ }^{1-3}$

Pathoanatomical studies showed that a degeneration of both the lower motor and primary sensory neurons represent the underlying pathological process for the clinical symptoms. ${ }^{4}$ The pathogenetic link between the abnormally expanded CAG trinucleotide repeat in the first exon of the androgen receptor gene which is found in affected patients and the depletion of the anterior horn cells and the primary sensory neurons with consecutive axonal degeneration of the dorsal root fibres has not been established yet. ${ }^{45}$ Although central and peripheral sensory conduction has been shown to be highly abnormal with absent or markedly prolonged sensory action potentials, most of the time the clinical findings of only a little sensory impairment do not correspond well to this electrophysiological constellation. ${ }^{13}$ We report sensory ataxia as the initial clinical symptom in a patient with X-BSNP.

A 63 year old retired journalist felt like "walking on pillows" for the first time when he was 45 years old. During the subsequent years the distally accentuated and symmetric loss of sensibility for touch, temperature, pain, position, and vibration was progressive in the legs - and later-also in the arms. At the age of 48 he noticed fasciculations of the facial muscles and a slow development of a painless, bilateral weakness of the proximal muscles of the lower and upper limbs. No related disease was found in his father's family; nothing is known about the maternal side of his family history.

The clinical examination of the patient showed a severe sensory gait ataxia as well as a dyspraxia of his hands. Other symptoms were a tremor of the hands and occasional spasms of the oral and pharyngeal musculature. The functions of other cranial nerves were normal. Spontaneous fasciculations of the buccal muscles and less often of the proximal and distal limb musculature were seen. Deep tendon reflexes could generally not be detected and there were no pathological reflexes. A proximally accentuated weakness and amyotrophy of the legs and arms as well as a distally accentuated hypaesthesia for all qualities was found. There were no cognitive deficits, cerebellar ataxia, or gynaecomastia.

Laboratory results were not abnormal (including plasma testosterone, follicle stimulating hormone, luteinising hormone, and glucose tolerance) except for a raised creatine kinase (354 U/1). The CSF examination also showed no abnormalities. Motor nerve conduction velocities were only slightly reduced whereas sensory action potentials were absent. Electromyography showed the typical features of chronic denervation in the proximal muscles of the lower and upper limbs as well as in the tongue. Motor evoked potentials showed normal central conduction times but partially prolonged latencies with stimulation of the cervical and lumbal roots. With tibial and median nerve stimulation no somatosensory evoked potentials were found neither at the cervical or lumbal nor at the cortical recording sites. Brain MRI was normal. The genetic analysis showed $42 \mathrm{CAG}$ trinucleotide repeats within the androgen receptor gene (normal length 11-34 repeats), which is a valuable criterion in the diagnosis of X-BSNP. ${ }^{5}$

The example of our patient shows that the electrophysiological findings of the sensory system may correspond well to the clinical syndrome in X-BSNP. It is not clear why patients with X-BSNP in most cases do not show significant sensory impairment although substantial loss of the primary sensory neuron has been proved. We hope that findings as in this case report may be an incentive for us to work for a better understanding of the problem as to why a specific neuronal degeneration can lead to a less specific pattern of clinical symptoms.

ANSGAR BUECKING ROBERT PFISTER

Department of Neurology, Zentralklinikum Augsburg, Stenglinstrasse 2, D-86156 Augsburg, Germany

Correspondence to: Dr Robert Pfister

1 Harding AE, Thomas PK, Baraitser M, et al. $\mathrm{X}$-linked recessive bulbospinal neuronopathy: a report of 10 cases. $\mathcal{F}$ Neurol Neurosurg Psychiatry 1982;45:1012-19.

2 Kennedy WR, Alter M, Sung JH. Progressive proximal spinal and bulbar muscular atrophy of late onset. A sex-linked recessive trait. Neurology (Minneapolis) 1968;18:671-80.

3 Wilde J, Moss T, Thrush D. X-linked bulbospinal neuronopathy: a family study of three patients. I Neurol Neurosurg Psychiatry 1987;50: patients.

4 Sobue G, Hashizume Y, Mukai E, et al. X-linked recessive bulbospinal neuronopathy. A clinicopathological study. Brain 1989;112:209-32.

5 La Spada AR, Paulson HL, Fischbeck KH. Trinucleotide repeat expansion in neurological disease. Ann Neurol 1994;36:814-22.

\section{Neuroleptic malignant syndrome without fever: a report of three cases}

Although fever is considered to be a cardinal feature of neuroleptic malignant syndrome, we report on three patients who were afebrile but had all the other features of the neuroleptic malignant syndrome. This paper highlights the need to suspect neuroleptic malignant syndrome and immediately initiate investigation and appropriate management in any patient who develops rigidity and clouding of consciousness while receiving antipsychotic medication, thus averting potentially lethal sequelae such as death.

The neuroleptic malignant syndrome (NMS) is an uncommon but potentially fatal idiosyncratic reaction characterised by the development of altered consciousness, hyperthermia, autonomic dysfunction, and muscular rigidity on exposure to neuroleptic (and probably other psychotrophic) medications. ${ }^{12}$

According to the DSM IV criteria, ${ }^{3}$ prominence has been given to signs of increase in temperature $\left(>39^{\circ} \mathrm{C}\right)$ and muscular rigidity. These must be accompanied by two or more of: diaphoresis, dysphagia, tremor, incontinence, altered consciousness, tachycardia, blood pressure changes, leucocytosis and raised creatine kinase concentrations. Some researchers have also advocated that a pyrexia in excess of $38^{\circ} \mathrm{C}$ or $39^{\circ} \mathrm{C}$ is necessary for the diagnosis of NMS. ${ }^{4-5}$ However, on reviewing the literature since 1965, we found three previous case reports highly suggestive of NMS occurring without fever. ${ }^{6-8}$ We report three patients who had all the major features of NMS but were afebrile during the entire course of their illness. These cases were seen within a 1 year period from July 1998 to July 1999.

A 52 year old man who was on treatment for postpsychotic depression presented after an act of deliberate self poisoning with a 